\title{
Input-specific Induction of Cerebellar Long-term Depression Does Not Require Presynaptic Alteration
}

\author{
David J. Linden \\ Department of Neuroscience \\ Johns Hopkins University School of Medicine \\ Baltimore, Maryland 21205
}

\section{Abstract}

In cerebellar long-term depression (LTD), conjunctive stimulation of parallel fiber (PF) and climbing fiber (CF) inputs to a Purkinje neuron result in a selective depression of PF-Purkinje neuron synaptic strength. This system is attractive for the study of neuronal information storage, both because of its duration and because it demonstrates input specificity. The mechanisms underlying input specificity in this system are not known, but they could involve presynaptic alterations, postsynaptic alterations, or some combination of both. To allow for an unambiguous analysis of postsynaptic processes, an LTD induction protocol has been developed using cultured cerebellar cells in which pulses of quisqualate and direct Purkinje neuron depolarization replace $P F$ and $C F$ stimulation, respectively. Input specificity is retained in this reduced system. When multiple, nonoverlapping quisqualate application sites are used, LTD is confined to those sites that are stimulated during depolarization. This property of LTD induction is also preserved under conditions where both spontaneous and evoked neurotransmitter releases are reduced or eliminated, indicating that postsynaptic alterations are sufficient to confer input specificity. Input-specific LTD may also be induced by local application of a protein kinase $C$ (PKC) activator (1-oleoyl-2-acetylglycerol) together with direct Purkinje neuron depolarization, suggesting that input-specific LTD results from the conjunction of a spatially broad $\mathrm{Ca}$ signal mediated by Purkinje neuron depolarization, together with a spatially constrained PKC-activating signal mediated by quisqualate application.

\section{Introduction}

In recent years a major focus of research on information storage in the brain has been the examination of long-term alterations in synaptic strength that result from particular patterns of activity. Numerous model systems have emerged in this endeavor, including homosynaptic long-term potentiation (LTP) and long-term depression (LTD), most frequently studied in the hippocampus and neocortex, and a unique form of associative homosynaptic LTD studied in the cerebellum. Although these forms of synaptic modification share the property of temporal persistence, they result from different patterns of activity and have varying consequences for the transmission of neuronal signals (Linden 1994). However, all three of these model systems also share the property of input specificity: The alteration in synaptic strength induced by a particular pattern of activity is confined to those synapses active at the time of induction. Most neurons in the brain receive many synaptic contacts, typically $1,000-10,000$ per cell (Noback and Demerest 1981). The integration of these synaptic signals is an important aspect of neuronal computation. As such, the ability to produce long-term modifications in synaptic strength that are specific to a given synapse (or small group of synapses) is critical for information storage in an assembly of neurons.

The cellular mechanisms that underlie input specificity of long-term synaptic changes are not well understood. There are several schemes that may be hypothesized to confer input specificity. First, a presynaptic signal that is confined to acti-

LEARNING \& MEMORY 1:121-128 @ 1994 by Cold Spring Harbor Laboratory Press ISSN1072-0502/94 \$5.00

$$
\begin{array}{llllllll}
L & E & A & R & N & I & N & G \\
\begin{array}{l}
\boldsymbol{X} \\
121
\end{array} & M & E & M & O & R & Y
\end{array}
$$


vated fibers could be sufficient to cause an alteration of neurotransmitter release from those fibers. Second, a presynaptic signal confined to afferent fibers could be necessary but not sufficient to cause an alteration in transmitter release. In this case, an alteration would be induced only when this presynaptic signal is present together with a retrograde signal of postsynaptic origin. Third, a retrograde signal of postsynaptic origin could be sufficient to induce an alteration of transmitter release, but this signal must be spatially constrained such that it affects only a small number of nearby presynaptic terminals. Fourth, a spatially constrained postsynaptic signal could be sufficient to cause a local alteration in postsynaptic sensitivity to transmitter. Fifth, a spatially constrained postsynaptic signal could be necessary to induce a local alteration in postsynaptic activity but can only do so when it is present together with some other signal of postsynaptic origin. In addition, some, but not all, of these mechanisms are capable of working in combination to yield input-specific alterations of synaptic strength.

Cerebellar LTD is induced by coactivation of climbing fiber (CF) and parallel fiber (PF) inputs to a Purkinje neuron (Ito et al. 1982) and is confined to those PF-Purkinje neuron synapses that are active at the time of $\mathrm{CF}$ activation (Ekerot and Kano 1985). This property is particularly important for the integration of synaptic signals by Purkinje neurons, as they receive an unusually large number of excitatory contacts, typically 150,000 200,000 PF synapses per cell. CF stimulation is thought to contribute to induction of cerebellar LTD by activating voltage-gated Ca channels, which causes a large increase in intracellular Ca. The $\mathrm{Ca}$ increase associated with CF activation is widely distributed throughout the Purkinje neuron dendritic arbor (Ross and Werman 1987; Konnerth et al. 1992). Support for this mechanism of CF action comes primarily from studies showing that CF activation may be replaced by direct depolarization of the Purkinje neuron soma if that depolarization is sufficient to activate voltagegated Ca channels (Crepel and Krupa 1988; Hirano 1990; Linden et al. 1991; Konnerth et al. 1992) and the observation that LTD induction may be blocked by postsynaptic application of Ca chelator (Sakurai 1990; Linden et al. 1991). PF stimulation contributes to LTD induction through the release of glutamate, which acts on both AMPA and metabotropic receptors. As such, PF activation may be replaced in the LTD induction protocol by pulses of exogenous glutamate or quisqualate (Kano and Kato 1987; Linden et al. 1991; Shigemoto et al. 1993). LTD may be monitored by recording the Purkinje neuron response to either PF activation or pulses of exogenous glutamate, quisqualate, or AMPA. The detection of LTD by test pulses of exogenous excitatory AMPA receptor agonists may be seen following LTD induction using either a glutamate/depolarization conjunction protocol (Linden et al. 1991; Shigemoto et al. 1993) or a PF activation/depolarization protocol (Crepel and Krupa 1988), suggesting that these test pulses activate a high proportion of synaptic (as opposed to extrasynaptic) receptors.

A protocol has been developed using embryonic mouse Purkinje neurons grown in culture (Schilling et al. 1991), in which CF and PF activation have been replaced by direct postsynaptic depolarization and application of exogenous quisqualate, respectively, facilitating the analysis of postsynaptic mechanisms (Linden et al. 1991, 1993; Linden and Connor 1991). This study examines whether postsynaptic processes are sufficient to confer input specificity on cerebellar LTD in a tissue culture system and attempts to determine which particular signals might be necessary.

\section{Materials and Methods}

Mouse cerebellar cultures were prepared and maintained according to the protocol of Schilling et al. (1991). Cultures were maintained in vitro for 10-21 days at the time of use in electrophysiological experiments. Perforated patch recording from Purkinje neurons was done essentially as described previously (Linden et al. 1991, 1993). Briefly, nystatin patch electrodes (Horn and Marty 1988) were attached to Purkinje neuron somata and were used to apply a holding potential of $-\mathbf{8 0}$ $\mathrm{mV}$. Iontophoresis electrodes (1- $\mu \mathrm{m}$ tip diam.) were filled with $10 \mathrm{~mm}$ quisqualate (in $10 \mathrm{~mm}$ HEPES at $\mathrm{pH} 7.2$ with $\mathrm{NaOH}$ ) or $10 \mathrm{~mm}$ AMPA (in $10 \mathrm{~mm}$ HEPES at $\mathrm{pH} 7.1$ with $\mathrm{NaOH}$ ) and were positioned $\sim 20 \mu \mathrm{m}$ away from large caliber dendrites (see Fig. 1a). Alternating test pulses of quisqualate were delivered to the two test sites with negative current pulses ( $750 \mathrm{nA}, 30$ - to 150 - msec duration ) applied at a frequency of $0.05 \mathrm{~Hz}$. After acquisition of $15 \mathrm{~min}$ of baseline responses, LTD was induced at a single site by pairing six successive quisqualate test pulses at that site with six 4-sec depolarization steps to $0 \mathrm{mV}$, timed so that

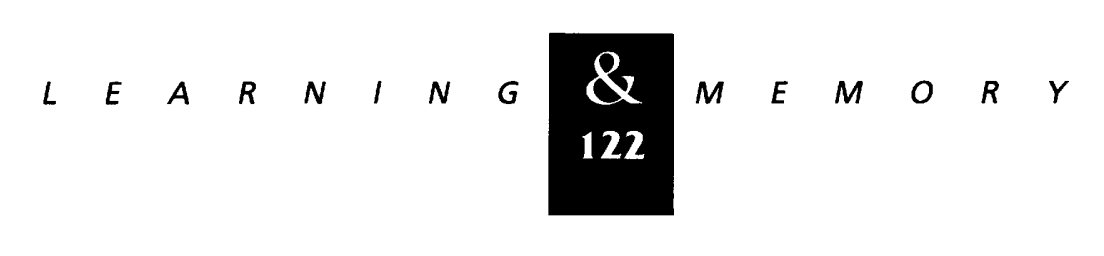


the depolarization onset preceded the quisqualate pulse by $500 \mathrm{msec}$. Cells were bathed in a solution that contained $\mathrm{NaCl}(140 \mathrm{~mm}), \mathrm{KCl}(5 \mathrm{~mm}), \mathrm{CaCl}_{2}$ (2 mM), $\mathrm{MgCl}_{2}(0.8 \mathrm{~mm})$, HEPES (10 mM), glucose $(10 \mathrm{~mm})$, tetrodotoxin $(0.0005 \mathrm{~mm})$, and picrotoxin $(0.1 \mathrm{~mm})$, adjusted to $\mathrm{pH} 7.35$ with $\mathrm{NaOH}$, which flowed at a rate of $0.5 \mathrm{ml} / \mathrm{min}$. The recording electrode contained $\mathrm{K}_{2} \mathrm{SO}_{4}(95 \mathrm{mM}), \mathrm{KCl}(15$ $\mathrm{mM}), \mathrm{MgCl}_{2}(8 \mathrm{~mm})$, and HEPES (10 $\left.\mathrm{mm}\right)$, adjusted to $\mathrm{pH} 7.35$ with $\mathrm{KOH}$. Patch electrodes were pulled from N51A glass and polished to yield a resistance of 2-5 $\mathrm{M} \Omega$ when measured with normal salines in the recording electrode and bath. Nystatin $(250 \mu \mathrm{g} / \mathrm{ml})$ was added to the recording electrode saline. This concentration gave access resistance to the cell that was typically $<10 \mathrm{M} \Omega$. Membrane currents evoked by application of quisqualate were recorded with an Axopatch 200A amplifier in resistive voltage-clamp mode and stored on a chart recorder that imposed a 0 - to $30-\mathrm{Hz}$ bandpass. Experiments were conducted at $20-24^{\circ} \mathrm{C}$.

Phorbol-12,13-dibutyrate (PDBu, from LC Services Corp.) and 1-oleoyl-2-acetylglycerol (OAG, from Sigma) were prepared as stock solutions in $10 \%$ dimethylsulfoxide (DMSO) prior to dilution in external saline. For local application, a micropipette with a tip diameter of 3-5 $\mu \mathrm{m}$ was filled with either $0.2 \mu \mathrm{M}$ PDBu or $20 \mu \mathrm{M}$ OAG and connected to a source of positive pressure (2-6 psi, General Valve Corp.). This micropipette was positioned within $5 \mu \mathrm{m}$ of a Purkinje neuron dendrite. A much larger (50- to $100-\mu \mathrm{m}$ tip diam.) suction pipette was also positioned directly opposite the ejection pipette to remove drug-containing saline. This arrangement produced a stream of drug-containing saline that could be restricted to a section of dendrite $\sim 10 \mu \mathrm{m}$ long as estimated by observing the flow of a dye-containing test solution.

Rhodamine 123 is a vital stain for mitochondria that may be used to image presynaptic terminals in neuronal culture (Yoshikami and Okun 1984). Cultures were incubated with $5 \mu \mathrm{M}$ rhodamine 123 in external saline for $20 \mathrm{~min}$ at room temperature on the stage of the inverted microscope where the electrophysiological experiments were conducted and were then washed with external saline $(1 \mathrm{ml} / \mathrm{min})$ for $10 \mathrm{~min}$ prior to imaging. Epifluorescence illumination at $481 \mathrm{~nm}$ was provided by excitation of coumarin 481 dye by a pulsed nitrogen laser $(337 \mathrm{~nm})$ operating at $20 \mathrm{~Hz}$ (Laser Sciences Inc.). This light was passed through a fiberoptic conduit to the epifluores- cence train of a Zeiss Axiovert 100 equipped with a $100 \times 1.25$ NA oil-immersion objective. Emission at $505 \mathrm{~nm}$ was passed through a $505-\mathrm{nm}$ dichroic mirror and was focused on the chip (Thompson 7883) of a slow-scan cooled CCD camera (Photometrics $\mathrm{CH} 250$ ). Exposure times were 200-500 msec. This technique allowed for the clear visualization of viable synaptic terminals and for reliable confirmation of their destruction.

\section{Results}

Perforated-patch recordings were made from cultured embryonic mouse Purkinje neurons. Currents evoked by iontophoretic application of quisqualate to two separate sites on the dendritic arbor were recorded from Purkinje neurons clamped to a holding potential of $-80 \mathrm{mV}$ and bathed in tetrodotoxin/picrotoxin saline. As illustrated in Figure 1a, frequently a "bipolar" type of Purkinje neuron was chosen to facilitate nonoverlapping application of quisqualate, which activates both AMPA and metabotropic receptors (Sugiyama et al. 1989). Following establishment of a baseline level of response at the two separate test sites with alternating pulses given at low frequency $(0.05 \mathrm{~Hz})$, six 4-sec-long step depolarizations to $0 \mathrm{mV}$ were applied together with quisqualate pulses at stimulation site 1 and alternating test pulses were resumed (Fig. 1b,c). Conjunctive quisqualate/depolarization applied to site 1 resulted in persistent depression of responses to site 1 test pulses, leaving currents evoked by site 2 stimulation unaltered. At $t=30 \mathrm{~min}$, conjunctive stimulation at site 2 induced a similar depression to test pulses at that location and produced no further alteration of site 1 responsivity. Thus, input-specific LTD may be induced in culture without direct electrical activation of presynaptic terminals and may be monitored in the same manner. It should be noted that although Purkinje neurons with a bipolar morphology provide the greatest possible separation of stimulation sites, input-specific cerebellar LTD has also been demonstrated in cultured Purkinje cells that display a unipolar morphology similar to that seen in vivo. In this case, using smaller quisqualate pulses, input-specific LTD could be seen at sites separated by $\sim 100 \mu \mathrm{m}$ in the same dendritic arbor (data not shown).

Although this experiment suggests that presynaptic processes are not required for input-specific induction of LTD, it is not definitive. The

$$
\text { ……․ }
$$


b
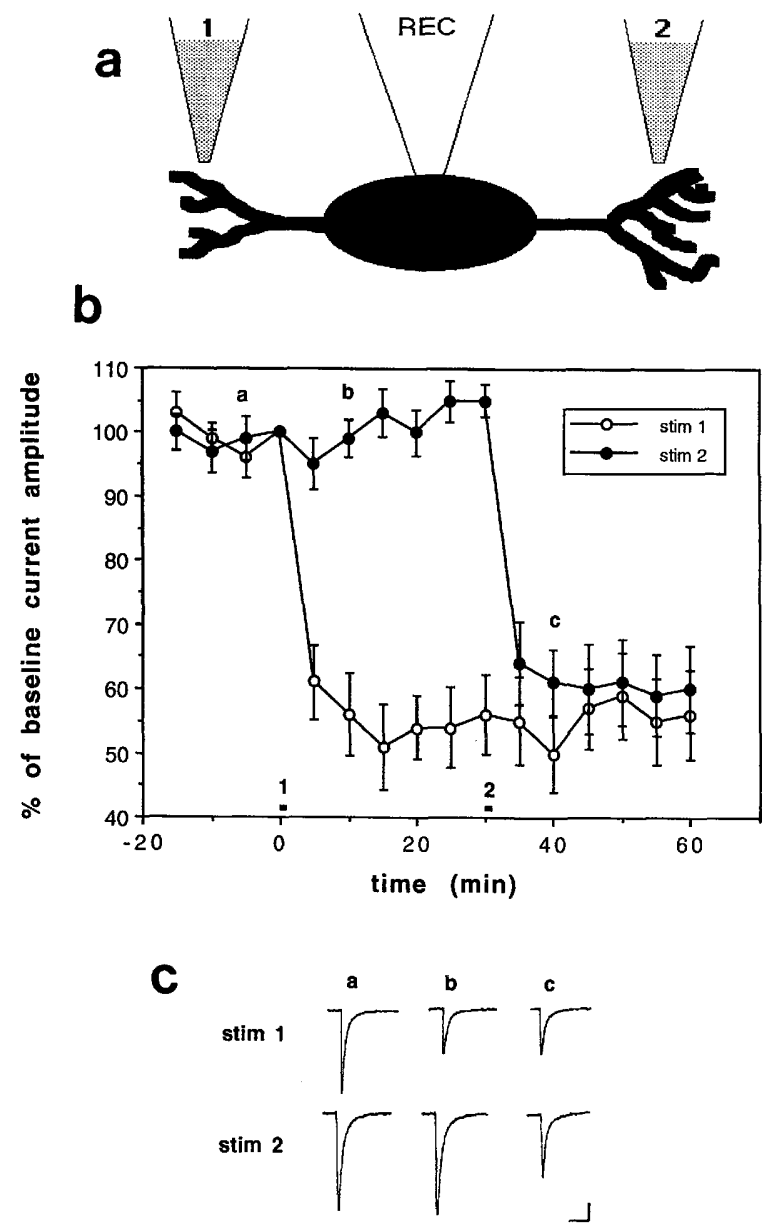

Figure 1: Input-specific induction of cerebellar LTD in a cell culture system. (a) A schematic illustration of the preparation: a perforated-patch recording electrode (REC) was used to record currents evoked by ejection of quisqualate from two separate iontophoretic electrodes (labeled 1 and 2) at two different sites. The recording electrode was also used to apply depolarizing voltage commands during LTD induction. (b) Quisqualate/depolarization conjunction at site 1 resulted in a selective depression of site 1 responsivity (site $1=54.0 \pm 5.0 \%$ of baseline at $t=20 \mathrm{~min}$; site $2=99.6 \pm 3.5$ ). Thirty minutes later, quisqualate/depolarization conjunction at site 2 resulted in a depression of site 2 responsivity that did not alter responsivity further at site 1 (site $1=$ $58.7 \pm 6.7 \%$ of baseline at $t=50 \mathrm{~min}$; site $2=61.0$ \pm 6.6 ). Each point represents the mean \pm S.E.M. of values recorded in 12 different cells. (c) Representative current traces corresponding to the times indicated on the graph in $b$. Each trace is a single response, and all traces were recorded in the same cell. Scale bars, $2 \mathrm{sec}, 40 \mathrm{pA}$.

Purkinje neurons grown in this culture system receive synaptic contacts, and although most synaptic transmission is abolished by the addition of tetrodotoxin/picrotoxin saline, some release persists under these conditions as indicated by the presence of spontaneous EPSCs that are blocked by kynurenate (data not shown). It is possible that the level of spontaneous release could be increased either directly, as a result of a presynaptic action of quisqualate, or indirectly, by activation of the Purkinje neuron resulting in K-efflux or some other retrograde signal. Therefore, two manipulations were performed to minimize the contribution of presynaptic processes. First, at the outset of the experiment, adenosine ( $100 \mu \mathrm{M})$ was included in the external saline to suppress spontaneous transmitter release (for review, see Dunwiddie 1990 ). In the cerebellum, large numbers of adenosine receptors are present on PF terminals (Goodman et al. 1983) and application of adenosine has been shown to potently block evoked PFmediated, but not CF-mediated, synaptic drive (Kocsis et al. 1984). Addition of adenosine ( 100 $\mu \mathrm{M})$ to the external saline reduced the frequency of spontaneous synaptic currents to $<10 \%$ of baseline values measured using either perforatedpatch or conventional whole-cell recording, the latter using a Cs-containing recording electrode saline (data not shown). Second, Purkinje neurons were physically isolated by scraping away adjacent cellular material in the culture dish, returning the dish to the incubator for $18-24 \mathrm{hr}$, and then conducting two-site LTD induction as in Figure 1. Following experiments with scraping, living cultures were stained with rhodamine 123 , a vital stain for mitochondria that may be used to image presynaptic terminals in neuronal culture (Yoshikami and Okun 1984), to confirm the absence of viable terminals on the isolated Purkinje cell. Neither application of adenosine nor physical isolation, nor the two treatments in combination interfered with the induction of input-specific LTD (Table 1). These findings strongly suggest that postsynaptic processes are sufficient to confer input specificity on cerebellar LTD in culture.

The question remains as to which signal, or signals, is required postsynaptically to induce LTD in an input-specific manner. Previous work has indicated that three postsynaptic processes are required to induce cerebellar LTD in culture (for review, see Linden and Connor 1993). These are Ca influx via voltage-gated channels (as produced by $\mathrm{CF}$ activation or direct depolarization of the Purkinje neuron), Na influx via AMPA receptorassociated ion channels (Linden et al. 1993), and activation of metabotropic receptors and the con-

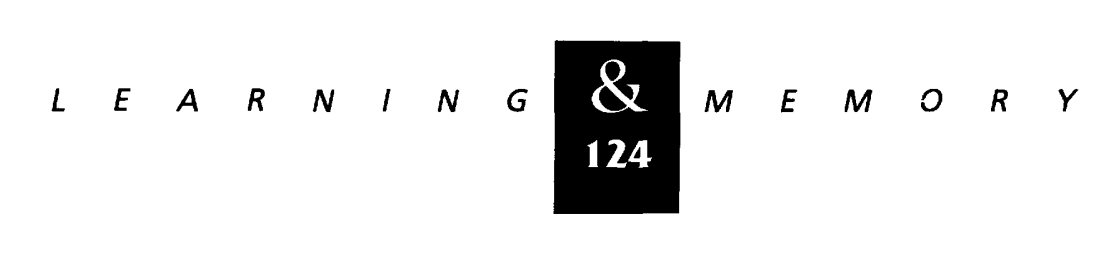


Table 1: Input specificity of cerebellar LTD is maintained when presynaptic processes are disrupted

\begin{tabular}{lccc}
\hline Treatment & LTD induction frequency & $\begin{array}{l}\text { Stim 1 LTD amplitude } \\
\left(_{\%} \text { of baseline }\right)^{b}\end{array}$ & $\begin{array}{l}\text { Stim 2 LTD amplitude } \\
(\% \text { of baseline })^{\mathrm{c}}\end{array}$ \\
\hline Control $(\mathrm{TTX}+\mathrm{PTX})$ & $11 / 12$ & $56 \pm 6.2$ & $60 \pm 6.6$ \\
Isolated & $6 / 6$ & $59 \pm 9.6$ & $53 \pm 8.0$ \\
Adenosine $(100 \mu \mathrm{M})$ & $7 / 8$ & $53 \pm 8.5$ & $61 \pm 9.5$ \\
Isolated + adenosine & $6 / 6$ & $54 \pm 8.9$ & $59 \pm 7.7$ \\
\hline
\end{tabular}

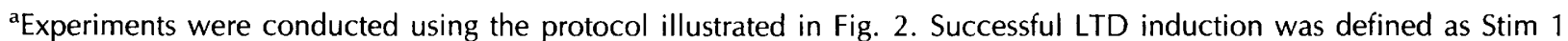
amplitude $<85 \%$ of baseline at $t=30 \mathrm{~min}$. In no case did LTD induction fail at Stim 1 and succeed at Stim 2. Amplitude measures that follow include failures.

${ }^{b}$ Measured at $t=30 \mathrm{~min}$.

${ }^{\mathrm{C}}$ Measured at $t=60 \mathrm{~min}$.

sequent stimulation of protein kinase C (PKC). The involvement of PKC is suggested by the observation that inhibition of PKC prevents LTD induction by quisqualate/depolarization conjunction (Linden and Connor 1991) and that application of phorbol esters, which are exogenous PKC activators, produces an LTD-like phenomenon (Crepel and Krupa 1988) that occludes LTD induced by conjunctive stimulation and may be blocked by PKC inhibitors (Linden and Connor 1991). It is not clear whether PKC activation is sufficient for LTD induction or whether some additional signal is required. In this regard, it should be noted that a previous study using the present cell culture protocol (Linden and Connor 1991) showed that the frequency of induction of depression by exogenous phorbol ester was 4 out of 11 when AMPA test pulses were not given during bath application of phorbol ester but 9 out of 9 when they were given together.

Which of these postsynaptic signals is spatially constrained in a manner that would allow for the induction of input-specific LTD? As Ca influx through voltage-gated $\mathrm{Ca}$ channels causes an increase in internal $\mathrm{Ca}$ concentration that is distributed widely across the dendritic arbor, it is not a good candidate for such a process. The consequences of local glutamate release (or quisqualate application in the present experiments), namely activation of AMPA and metabotropic receptors and the consequent stimulation of PKC, seem most likely to fulfill this requirement.

To evaluate this possibility, the PKC-activating phorbol ester PDBu was applied both locally and in the bath using the two-site stimulation protocol. As illustrated in Figure 2a, bath application of PDBu $(0.1 \mu \mathrm{M}$, at $t=0-10 \mathrm{~min})$ resulted in a de- pression of Purkinje neuron response to quisqualate measured with test pulses applied to two different sites. In a separate set of experiments, following quisqualate/depolarization conjunction at site 1 (at $t=0 \mathrm{~min}$ ), bath application of PDBu (at $t=20-30 \mathrm{~min}$ ) resulted in a depression of test pulse responses at site 2 that left the amplitude of the previously depressed response at site 1 unaltered (Fig. 2b). Finally, local application of PDBu $(0.2 \mu \mathrm{M}$, at $0-5 \mathrm{~min})$ to site 1 by microperfusion resulted in a specific depression of site 1 responses that was not altered by subsequent conjunctive stimulation of site 2 (at $t=40 \mathrm{~min}$; Fig. 2c). Local application of PDBu did not result in perturbation of resting $\mathrm{Ca}$ as measured by fura- 2 microfluorimetry (data not shown).

Although phorbol esters such as PDBu are potent exogenous activators of $\mathrm{PKC}$, it is not clear that they mimic endogenous routes of PKC activation. Whereas phorbol esters activate PKC by reducing the $\mathrm{Ca}$ concentration required for activation to intracellular resting levels, the natural activators of PKC (diacylglycerols, unsaturated fatty acids) are likely to act synergistically with intracellular Ca transients, and with each other, to cause PKC activation (Nishizuka 1992). In addition, phorbol esters have effects other than PKC activation. For example, they are activators of the enzyme phospholipase $A_{2}$ (Mallorga et al. 1980), which may or may not be activated as a consequence of metabotropic receptor activation in Purkinje neurons.

To address this issue, OAG, a somewhat more physiological activator of PKC, was employed. Unlike PDBu, local application of OAG $(10 \mu \mathrm{M}$ at $t=0-5 \mathrm{~min}$ ), to site 1 , together with AMPA test pulses did not result in a depression of Purkinje

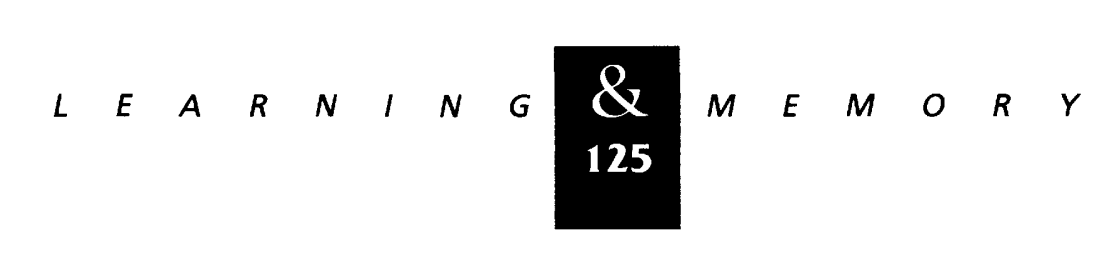



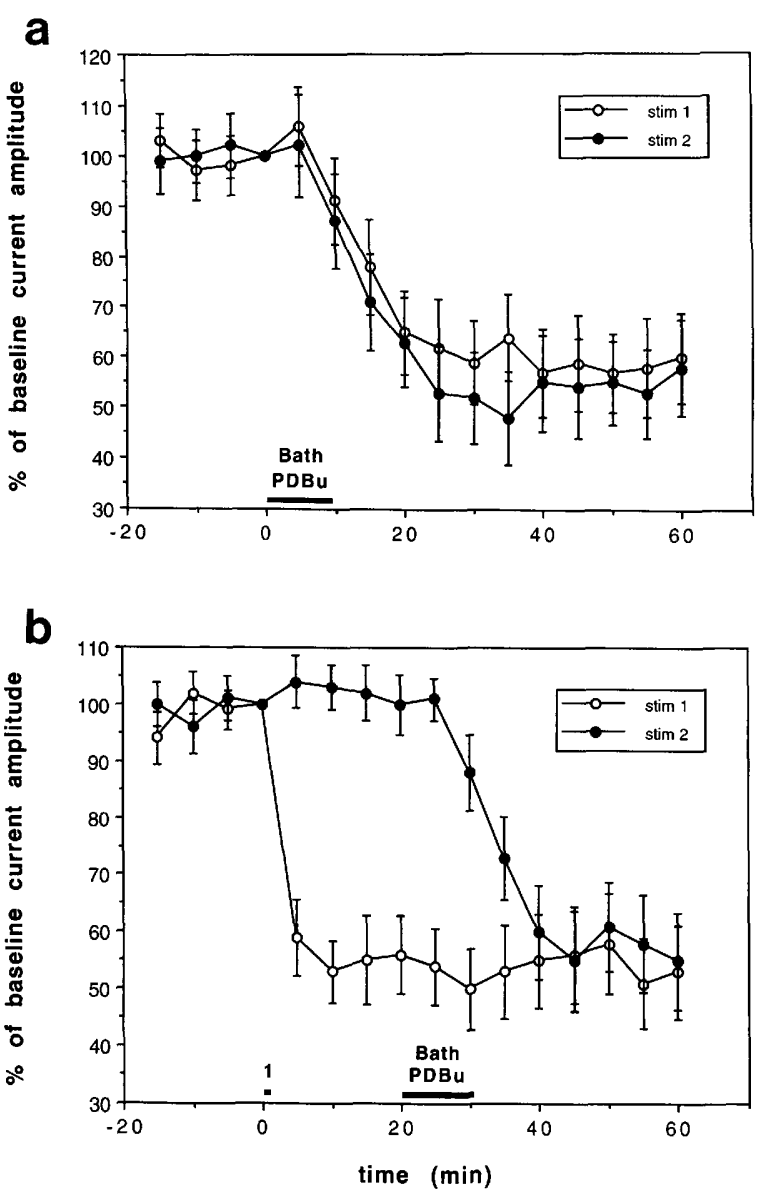

neuron responsivity monitored at either site (Fig. $3)$. However, when OAG was applied to site 1 $(t=30-35 \mathrm{~min})$, together with step depolarizations (10 steps to $-10 \mathrm{mV}, 4$ sec long, 20-sec interstep interval ) and AMPA test pulses, a depression specific to site 1 was induced. AMPA test pulses were used instead of quisqualate in this case because quisqualate/depolarization conjunction alone is sufficient to induce LTD (Linden et al. 1991 ).

\section{Discussion}

Taken together, these experiments suggest that input specificity of LTD is conferred, at least in part, by spatially constrained activation of PKC in the Purkinje neuron dendrite. It is likely that this spatially constrained activation results from the conjunction of a broad Ca signal contributed by direct depolarization of the Purkinje neuron (or by CF activation in the slice or intact cerebellum) and a constrained signal or set of signals con-

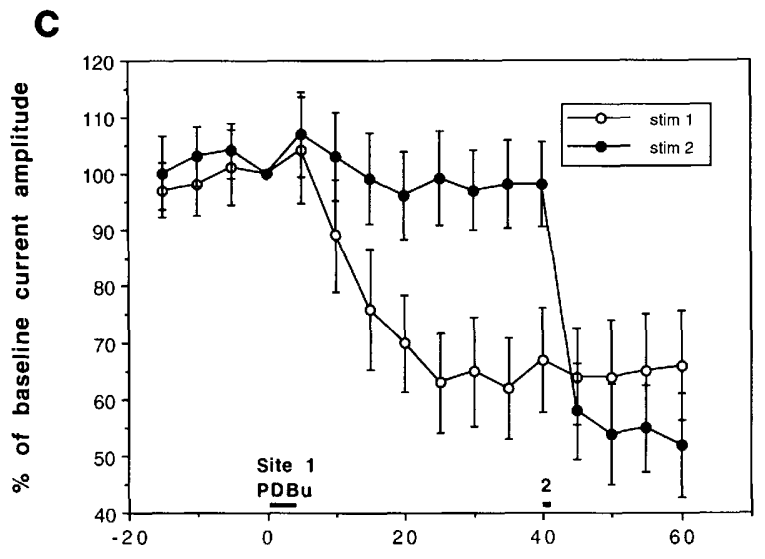

Figure 2: Site-specific depression may be induced by local application of PKC-activating phorbol esters. All experiments were conducted with $100 \mu \mathrm{M}$ adenosine in the external saline. (a) Bath application of PDBu resulted in a persistent depression monitored with quisqualate pulses at two separate sites. In both this and the following two experiments, test pulses were delivered to both sites during PDBu application. $n=5$ cells. (b) Bath application of PDBu caused a depression of quisqualate responsivity at site 2 but did not alter responses further at site 1 where LTD had been induced previously by quisqualate/ depolarization conjunction. $n=6$ cells. (c) Local application of PDBu at site 1 resulted in depression of site 1 responsivity that left site 2 unaltered (site $1=65.1 \pm 9.6 \%$ of baseline at $t=30 \mathrm{~min}$; site $2=97.4 \pm 7.2$ ) and did not interfere with the subsequent induction of depression at site 2 by quisqualate/ depolarization conjunction. $n=6$ cells.

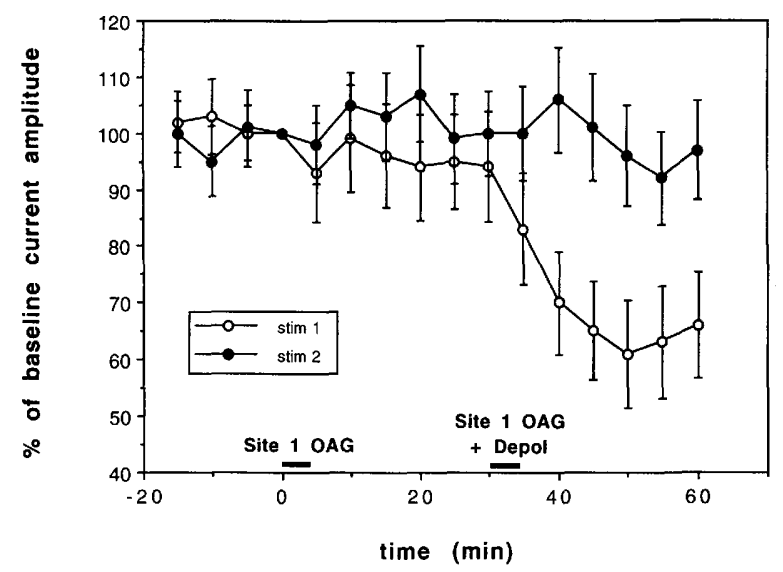

Figure 3: Induction of site-specific depression by the PKC activator OAG requires conjoint depolarization. Local application of OAG at site 1, together with AMPA test pulses, did not alter responsivity monitored at either site 1 or 2 . However, local application of OAG to site 1 combined with depolarizing commands sufficient to cause $\mathrm{Ca}$ entry resulted in a selective depression of site 1 responsivity. AMPA test pulses to both sites were continued throughout the OAG application periods. $n=7$ cells.

$$
\text { ……" 짐 }
$$


tributed by AMPA and metabotropic receptor activation (or PF activation). The role of PFs seems limited to simple release of glutamate upon stimulation. Alteration of glutamate release as a consequence of LTD induction does not appear to be necessary nor does release of any signal in addition to glutamate. This corresponds to the fifth type of model discussed in the introduction.

The mechanisms that confer input specificity on cerebellar LTD appear different from those operative in other model systems of synaptic plasticity. This is not surprising given that cerebellar LTD requires the simultaneous activation of two morphologically and functionally distinct fiber pathways, whereas most other model systems, such as hippocampal homosynaptic LTP and LTD, do not. In the hands of most investigators, attempts to induce hippocampal LTP without activation of presynaptic terminals have resulted only in shortterm potentiation (Zilberter et al. 1990; Malenka 1991, but see Cormier et al. 1993). It has also been suggested that input specificity of LTP in area CA1 of hippocampus is operative at the level of small polysynaptic domains rather than being explicitly constrained to activated synapses. Induction of LTP by pairing low-frequency stimulation of Schaffer collateral fibers with depolarization of a single postsynaptic CA1 pyramidal cell grown in slice culture resulted in the induction of LTP measured at both the depolarized cell and its near neighbors (Bonhoeffer et al. 1989). This phenomenon has been suggested to result from the diffusion of the short-lived gaseous messenger NO from the postsynaptic cell to adjacent neurons (Schuman and Madison 1994). The results of this study cannot exclude the possibility of such a local spreading mechanism (mediated by NO or any other diffusible messenger) in cerebellar LTD in culture.

Further analysis of the mechanisms of input specificity in cerebellar LTD (and other model systems) will depend largely on the ability to visualize the various candidate signals $(\mathrm{Ca}$, diacylglycerol, IP3, etc.) in the compartments in which they are produced and in which they interact. The potential role of dendritic spines in mediating compartmentation of these signals is likely to be particularly important.

\section{Acknowledgments}

Thanks go to D. Gurfel who provided skillful technical assistance and to T. Murphy and P. Manis who read earlier versions of this manuscript. This work was supported in part by U.S. Public Health Service grant MH51106. D.J.L. is a Klingenstein Fellow, an Alfred P. Sloan Research Fellow, and a McKnight Scholar.

The publication costs of this article were defrayed in part by payment of page charges. This article must therefore be hereby marked "advertisement" in accordance with 18 USC section 1734 solely to indicate this fact.

\section{References}

Bonhoeffer, T., V. Staiger, and A. Aertsen. 1989. Synaptic plasticity in rat hippocampal slice cultures: Local "Hebbian" conjunction of pre- and postsynaptic stimulation leads to distributed synaptic enhancement. Proc. Natl. Acad. Sci. 86: 8113-8117.

Cormier, R.J., M.D. Mauk, and P.T. Kelly. 1993. Glutamate iontophoresis induces long-term potentiation in the absence of presynaptic activity. Neuron 10: 907-919.

Crepel, F. and M. Krupa. 1988. Activation of protein kinase $\mathrm{C}$ induces a long-term depression of glutamate sensitivity of cerebellar Purkinje cells. An in vitro study. Brain Res. 458: $397-401$.

Dunwiddie, T.V. 1990. In Adenosine and adenosine receptors (ed. M. Williams), pp. 143-172. Humana Press, Totowa, NJ.

Ekerot, C.-F. and M. Kano. 1985. Long-term depression of parallel fibre synapses following stimulation of climbing fibres. Brain Res. 342: 357-360.

Goodman, R.R., M.J. Kuhar, L. Hester, and S.H. Snyder. 1983. Adenosine receptors: Autoradiographic evidence for their location on axon terminals of excitatory neurons. Science 220: 967-969.

Hirano, T. 1990. Depression and potentiation of the synaptic transmission between a granule cell and a Purkinje cell in rat cerebellar culture. Neurosci. Lett. 119: 141-144.

Horn, R. and A. Marty. 1988. Muscarinic activation of ionic currents measured by a new whole-cell recording method. J. Gen. Physiol. 92: 145-159.

Ito, M., M. Sakurai, and P. Tongroach. 1982. Climbing fibre induced depression of both mossy fiber responsiveness and glutamate sensitivity of cerebellar Purkinje cells. J. Physiol. 324: 113-134.

Kano, M. and M. Kato. 1987. Quisqualate receptors are specifically involved in cerebellar synaptic plasticity. Nature 325: 276-279.

Kocsis, J.D., D.L. Eng, and R.B. Bhisitkul. 1984. Adenosine selectively blocks parallel fiber-mediated synaptic potentials in rat cerebellar cortex. Proc. Natl. Acad. Sci. 81: 6531-6534.

Konnerth, A., J. Dreessen, and G.J. Augustine. 1992. Brief dendritic calcium signals initiates long-lasting synaptic depression in cerebellar Purkinje cells. Proc. Natl. Acad. Sci. 89: 7051-7055.

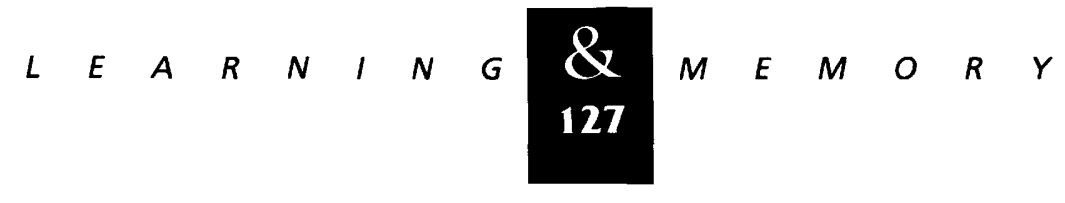




\section{Linden}

Linden, D.J. 1994. Long-term synaptic depression in the mammalian brain. Neuron 12: 457-472.

Linden, D.J. and Connor, J.A. 1991. Participation of postsynaptic PKC in cerebellar long-term depression in culture. Science 254: 1656-1659.

1993. Cellular mechanisms of long-term depression in the cerebellum. Curr. Opin. Neurobiol. 3: 401-406.

Linden, D.J., M. Smeyne, and J.A. Connor. 1993. Induction of cerebellar long-term depression in culture requires postsynaptic action of sodium ions. Neuron 11: 1093-1100.

Linden, D.J., M.H. Dickinson, M. Smeyne, and J.A. Connor. 1991. A long-term depression of AMPA currents in cultured cerebellar Purkinje neurons. Neuron 7: 81-89.

Malenka, R.C. 1991. Postsynaptic factors control the duration of synaptic enhancement in area CA1 of the hippocampus. Neuron 6: 53-60.

Mallorga, P., J.F. Tallman, R.C. Henneberry, F. Hirata, W.T. Strittmatter, and J. Axelrod. 1980. Mepacrine blocks beta adrenergic agonist-induced desensitization in astrocytoma cells. Proc. Natl. Acad. Sci. 77: 1341-1345.

Nishizuka, Y. 1992. Intracellular signaling by hydrolysis of phospholipids and activation of protein kinase C. Science 258: $607-614$.

Noback, C.R. and R.J. Demerest. 1981. The human nervous system, 3rd ed. p. 63. McGraw-Hill, New York.

Ross, W.N. and R. Werman. 1987. Mapping calcium transients in the dendrites of Purkinje cells from the guinea-pig cerebellum in vitro. J. Physiol. 389: 319-336.

Sakurai, M. 1990. Calcium is an intracellular mediator of the climbing fiber in induction of cerebellar long-term depression. Proc. Natl. Acad. Sci. 87: 3383-3385.

Schilling, K., M.H. Dickinson, J.A. Connor, and J.I. Morgan. 1991. Electrical activity in cerebellar cultures determines

Purkinje cell dendritic growth patterns. Neuron 7: 891-902.

Schuman, E.M. and D.V. Madison. 1994. Locally distributed synaptic potentiation in the hippocampus. Science 263: $532-536$.

Shigemoto, R., S. Nakanishi, and T. Hirano. 1993. Antibodies against a metabotropic glutamate receptor, mGLUR1, inhibit long-term depression in cerebellar culture. Neurosci. Res. (Suppl.) 18: 329.

Sugiyama, H., I. Ito, and M. Watanabe. 1989. Glutamate receptor subtypes may be classified into two major catagories: A study on Xenopus oocytes injected with rat brain mRNA. Neuron 3: 129-132.

Yoshikami, D. and L.M. Okun. 1984. Staining of living presynaptic nerve terminals with selective fluorescent dyes. Nature 310: 53-56.
Zilberter, Y.I., V.V. Uteshev, S.N. Sokolova, L.G. Motin, and H.H. Eremjan. 1990. Potentiation of glutamate-activated currents in isolated hippocampal neurons. Neuron 5: 597-602.

Received April 11, 1994; accepted in revised form May 16, 1994. 


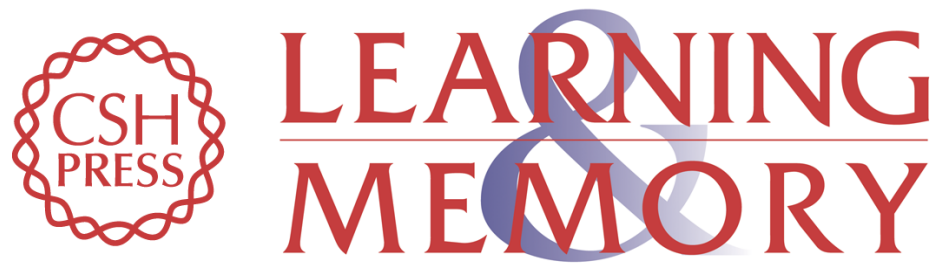

\section{Input-specific induction of cerebellar long-term depression does not require presynaptic alteration.}

D J Linden

Learn. Mem. 1994, 1:

Access the most recent version at doi:10.1101//m.1.2.121

References This article cites 27 articles, 10 of which can be accessed free at: http://learnmem.cshlp.org/content/1/2/121.full.html\#ref-list-1

License

Email Alerting Receive free email alerts when new articles cite this article - sign up in the box at the Service top right corner of the article or click here. 